\title{
EUS-guided drainage of ruptured liver abscess
}

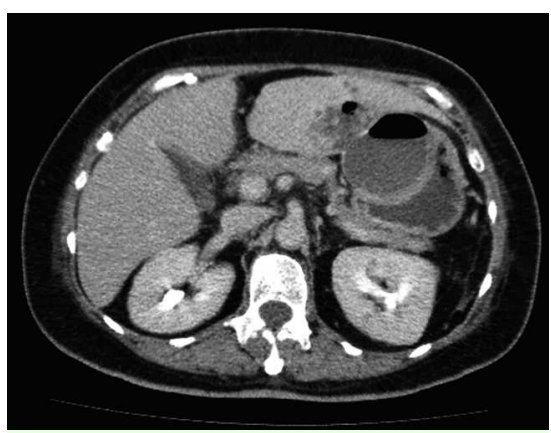

Fig. 1 Computer tomography image of the ruptured liver abscess showing communication with a walled-off subhepatic collection.

Liver abscesses are usually drained percutaneously. If drainage is inadequate, surgery may be necessary [1]. Endoscopic ultrasound (EUS)-guided drainage of pancreatic, pelvic, subphrenic, and splenic abscesses has been reported [2]. There has been one reported case of EUS-guided drainage of a well-encapsulated liver abscess [3]. A ruptured liver abscess is usually an indication for surgery [1]. We report a case of ruptured liver abscess with a walled-off left subhepatic collection that was successfully treated by EUS-guided drainage using a doublewire technique [4] that facilitated the placement of multiple stents.

A 58-year-old woman presented with a 1week history of fever and lethargy. There was fullness in the left upper abdomen but no peritonism. The woman was also in diabetic ketoacidosis. Computer tomography showed a ruptured left liver abscess communicating with a walledoff subhepatic collection measuring $10.7 \times 5.7 \mathrm{~cm}$ ( $\odot$ Fig. 1). The patient was treated with intravenous antibiotics and insulin. Percutaneous drainage was attempted but was unsuccessful, with minimal aspirate. The surgical risks were considered high, so the patient was referred for endoscopic drainage. The subhepatic abscess was visualized using a therapeutic linear echoendoscope (GFUCT160; Olympus, Tokyo, Japan) and punctured with a 19-gauge needle (EUSN-19-T; Cook Endoscopy, WinstonSalem, North Carolina, USA) ( Fig. 2) via a transgastric approach. A 480-cm, 0.035 -inch guide wire was inserted and the puncture needle was withdrawn. A 10-Fr Soehendra biliary dilator (Cook En-

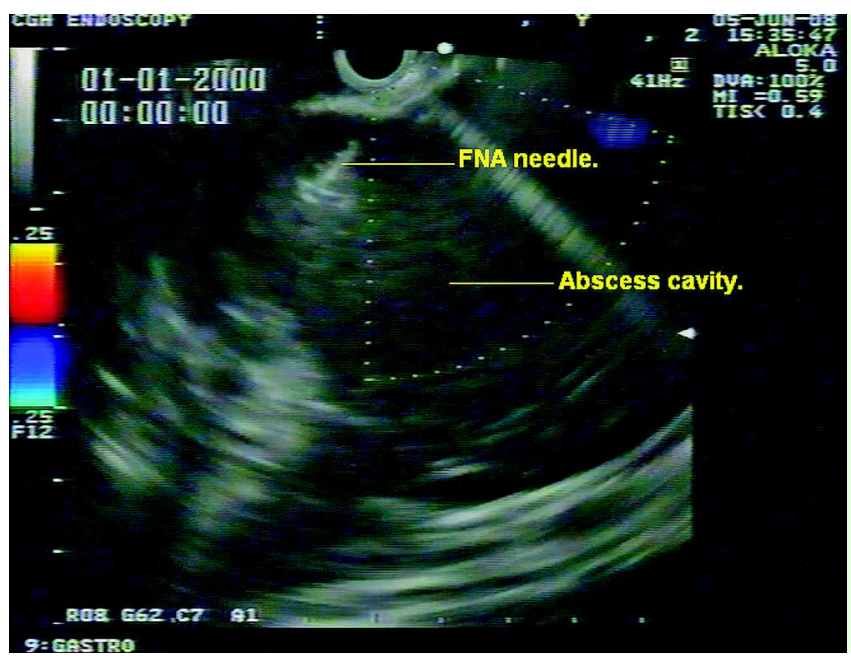

Fig. 2 Endoscopic ultrasound-guided puncture of the subhepatic abscess collection.

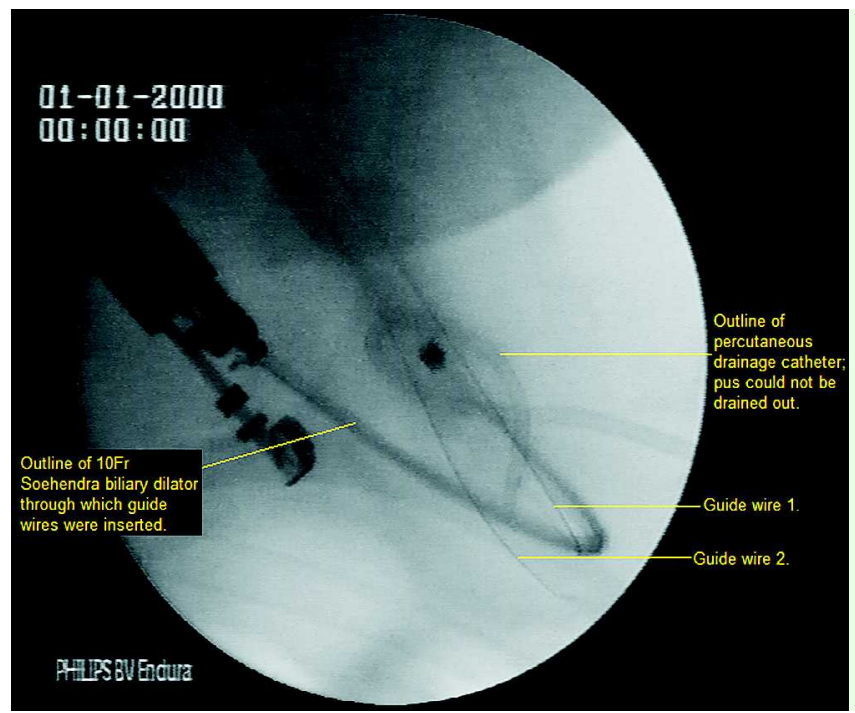

Fig. 3 Fluoroscopy showing two guide wires inserted through a $10-\mathrm{Fr}$ Soehendra dilator within the abscess cavity. The outline of a previously inserted percutaneous drainage catheter within the liver abscess can be seen; this catheter had minimal aspirate.

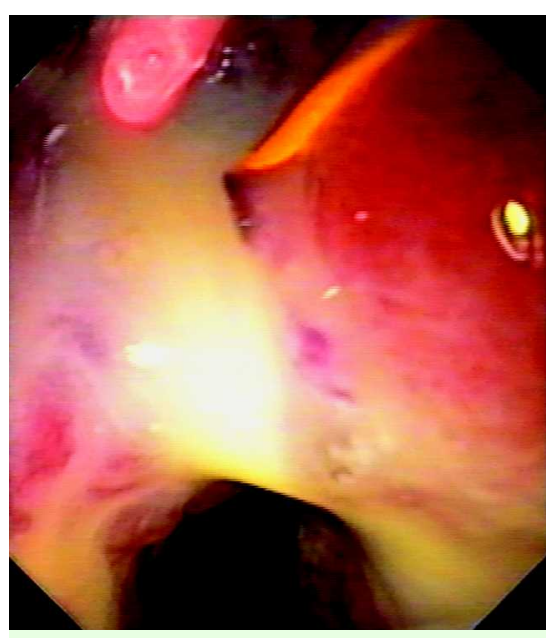

Fig. 4 Pus flowed out of the abscess cavity after placement of a single stent, obscuring the endoscopic view. The presence of another guide wire facilitated the placement of a second stent despite the poor endoscopic view.

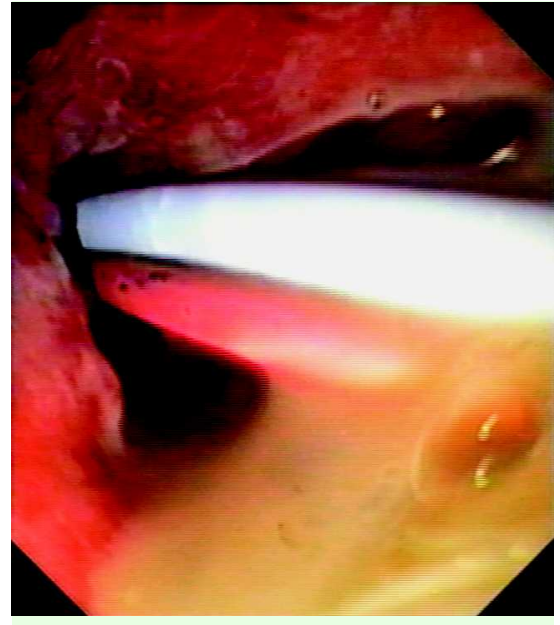

Fig. 5 Two transgastric stents were inserted for drainage of the abscess. 
doscopy) was inserted over the guide wire and a second 0.035 -inch guide wire was inserted through the dilator. The dilator was withdrawn, leaving two guide wires within the abscess cavity [4] ( 1 Fig. 3). Balloon dilation of the puncture site to $8 \mathrm{~mm}$ was performed (CRE; Boston Scientific, Natick, Massachusetts, USA). An 8-Fr and a 10-Fr 7-cm double pigtail stent were sequentially inserted ( $\bullet$ Figs. 4, 5). The procedure was completed within 30 minutes without complications. Resolution of the liver abscess and subhepatic collection was documented after 11 days and both stents were removed.

Endoscopy_UCTN_Code_TTT_1AS_2AG
T. L. Ang ${ }^{1}$, S. Seewald ${ }^{2}$, E. K. Teo ${ }^{1}$, K. M. Fock ${ }^{1}$, N. Soehendra ${ }^{2}$

1 Division of Gastroenterology, Department of Medicine, Changi General Hospital, Singapore

2 Department of Interdisciplinary Endoscopy, University Medical Center Hamburg-Eppendorf, Hamburg, Germany

\section{References}

1 Chung YF, Tan YM, Lui HF et al. Management of pyogenic liver abscesses - percutaneous or open drainage? Singapore Med J 2007; 48: $1158-1165$

2 Seewald S, Ang TL, Teng KYK et al. Innovation forum: EUS guided drainage of abdominal abscesses. Endoscopy 2008; (in press)

3 Seewald S, Imazu H, Omar S et al. EUS-guided drainage of hepatic abscess. Gastrointest Endosc 2005; 61: 495-498

4 Ang TL, Teo EK, Fock KM. EUS-guided drainage of infected pancreatic pseudocyst: use of a $10 \mathrm{Fr}$ Soehendra dilator to facilitate a double-wire technique for initial transgastric access (with videos). Gastrointest Endosc 2008; 68: $192-194$
Bibliography

DOI $10.1055 / \mathrm{s}-0028-1103468$

Endoscopy 2009; 41: E21 -E22

(c) Georg Thieme Verlag KG Stuttgart · New York . ISSN 0013-726X

Corresponding author

\section{T. L. Ang}

Division of Gastroenterology

Changi General Hospital

2 Simei St 3

Singapore 529889

Fax: +65-6781-6202

tiing_leong_ang@cgh.com.sg 